Isotope Division at Harwell maintains an advisory service to assist potential new users, and also showed some typical applications in the British Industries Fair.

Two applications that are being widely used are the measurement of the thickness of thin films by the attenuation of rays from a $\beta$-emitter, and the dis. persion of static electricity. In the case of the former, several instruments made commercially are already on the market. Another promising application is the use of $\gamma$-emitters for industrial radiography, and several isotopes for this purpose are already available in standardized source sizes. The present aim is to find a range of sources covering the energy region from $200 \mathrm{KeV}$. to about $1 \mathrm{MeV}$., which would be suitable for radiographs of steels and light alloys from in. up to 6 in. thick. Cobalt-60, with $\gamma$-ray energies of $1 \cdot 1$ and $1.3 \mathrm{MeV}$., tantalum-182 with an average of $1.125 \mathrm{MeV}$. and iridium-192 with an average of $0.5 \mathrm{MeV}$. all appear suitable, and other isotopes are being investigated.

It is sometimes forgotten that many of the artificially produced radioisotopes require chemical processing after they are taken out of the pile. Because of the short half-life of the most widely used isotopes, much of this processing has to be done at Harwell, including a production of phosphorus-32, iodine-131 and gold-198, each of the order of 1 curie per week: one suite in the new radiochemical laboratory is used almost entirely for this work.

Chemical processing of longer-lived isotopes, and syntheses of compounds with 'Iabelled' atoms, particularly carbon-14, are carried out at the Radiochemical Centre at Amersham, which became an outstation of the Establishment last April.

\section{Particle Accelerators}

The newest particle accelerator at Harwell, com. pleted earlier this year, is a $4-\mathrm{MeV}$. linear accelerator, similar to the Malvern accelerator previously de-

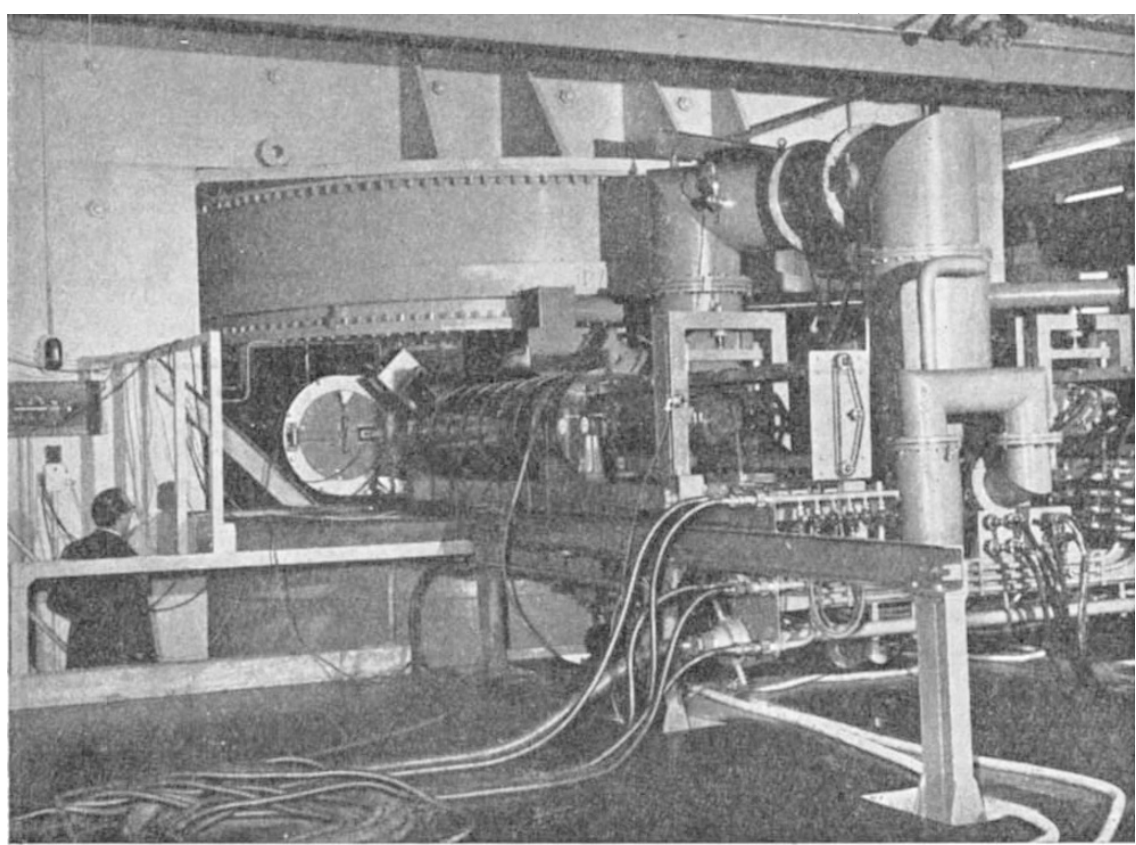

Fig. 2. 175-MoV. synchro-cyclotron at Harwell. The accelerating voltage is fed into this side of the machine from a radio-frequency transmitter. Crown copyright reserved scribed $^{1}$. It will be used principally for measuring the neutron cross-sections of reactor materials by the time of flight method. The accelerator produces pulses of electrons lasting 2 microseconds, with a beam current in the pulse of about 120 milliamperes. The electron beam strikes a heavy-metal target, so producing intense pulses of $\gamma$-rays. In this machine, the $\gamma$-rays are used to irradiate a beryllium target, which gives the neutrons required for experimental work.

Compared with other accelerators giving a similar output, the linear accelerator is both compact and cheap : because of these factors it is very suitable for deep X-ray therapy in hospitals, and some similar machines are to be built for this purpose.

The 175-MeV. synchro-cyclotron (Fig. 2), which started up last December ${ }^{2}$, has continued to work remarkably well and is now available full-time for experimental purposes. Some interesting results have already been obtained with it, and these were the subject of a recent communication in Nature ${ }^{3}$.

'Nature, 162, 859 (1948).

'Nature, 165, 90 (1950).

${ }^{3}$ Nature, 165, 967 (1950).

\section{FOURTH WORLD POWER CONFERENCE}

7 THE World Power Conference, founded in 1924, 1 has held plenary meetings in 1924 (London), 1930 (Berlin) and 1936 (Washington). Although sectional meetings have been held in intermediate years, including one at The Hague in 1947 on the subject of fuel economy, the Second World War caused a gap in plenary meetings after the Washington meeting extending until this year. The Fourth World Power Conference was held in London during July 10-15, under the patronage of Princess Elizabeth and the Duke of Edinburgh. The theme was "World Energy Resources and the Production of Power". The Conference, which was attended by representatives of more than forty nations, was opened by its president, Sir Harold Hartley, in the presence of a distinguished company, including representatives of the Governments of many of the nations represented. For discussion within four working days, the gathering had before it 155 papers and 19 general reports, each of which dealt with one of the sections into which the papers were divided.

There is anxiety throughout the world concerning reserves of energy. The demand for electricity has increased of late years at an exponential rate, and if the demand for coal, oil and gas has more nearly followed a straight-line law, the slope of the line has 
been such as to cause concern among individual nations as to when their own supplies of fossil fuels will become exhausted, and to the world in general as to possible sources of energy when there is no more coal or oil. Our present civilization is built on harnessing artificial sources of power to human needs ; the greater the productivity, the greater the consumption of coal and oil. The statement was made that if in Britain the same amount of power was used per head of population as in the United States, the whole of the country's present coal output would be needed to generate the electricity required.

In consequence of this position, there is the greatest activity all over the world to eke out coal reserves by using other sources of energy. Many nations, among whom are the Norwegians, the Swedes, the Canadians, the Finns, the Poles, the Austrians, the Portuguese, the French, the Swiss, and even the Americans, are developing their indigenous sources of water-power ; in many of these lands this meets most of the energy requirements. Other ideas are finding practical expression. There is a project at Abidjan on the Ivory Coast for using the potential thermal energy of sea-water existing by reason of the vertical temperature gradient of $68^{\circ} \mathrm{F}$. or more over a depth of $1,640 \mathrm{ft}$. in tropical seas ; a boiler heated by water at a temperature of $82^{\circ} \mathrm{F}$. would supply a turbine with steam at a corresponding pressure exhausting into a condenser cooled by water at $46^{\circ} \mathrm{F}$. A unique hydro-electric scheme is proposed in North Africa whereby the waters of the Mediterranean would be admitted to the Qattara Depression, providing some $300 \mathrm{MW}$. of hydro-electric capacity, the incoming water being disposed of by natural evaporation from the salt lake formed in the Depression. At Lardarello, in Italy, there is what the general reporter described as "a unique and epic achievement in engineering history" in which natural steam at 1518 atm. and $285-420^{\circ} \mathrm{F}$. is obtained, mixed with gases, from underground molten volcanic magma by putting down boreholes, up to $10,000 \mathrm{ft}$. in depth, capping them like an oil gusher when the initial eruption has quietened somewhat, and expanding the steam through turbines; since 1949 , power production from this source has been at the rate of more than 1,000 million $\mathrm{kWh}$. a year, and makes an important contribution to satisfying Italy's energy requirements. Wind-power and atomic energy are also under investigation. The planned international development of rivers by mutual agreement for the advantage of all nations through whose territory they flow was generally approved, the uses including power, irrigation, fishing and transport. Fuel economy is being scientifically pursued by all industrial nations; but one important source of waste appears to be virtually untouched-avoidance of loss of coal underground. The coal lost in mining bituminous coal in the United States, as an example, is generally cited as $34 \cdot 7$ per cent, a figure published by the U.S. Bureau of Mines twenty-five years ago, with the comment that more than half these losses were avoidable; present opinion is that this loss has since risen, perhaps to 50 per cent.

In 1924, British coal reserves were estimated as 137,166 million metric tons, which on an output of 200 million tons a year seemed comfortably sufficient for 685 years. The Regional Survey Committee of the Ministry of Fuel and Power in 1945 arrived at a total reserve of 44,714 million metric tons, plus some explored but probable additional reserves. If this estimate does not allow for mining losses, Great
Britain's resources may be sufficient for not much longer than 150 years. Hydro-electric resources of the British Isles can provide only a modest proportion of the total energy requirements of the population. In 1948 the output of hydro stations under the British Electricity Authority was 517 million $\mathrm{kWh}$. It is believed that a total of about 12,000 million $\mathrm{kWh}$. could be generated in Scotland and a further 2,365 million $\mathrm{kWh}$. from a Severn barrage. A total of 20,000 million $\mathrm{kWh}$. appears to be the limit in the present state of knowledge. This is less than half the electricity distributed through the public supply in Great Britain in the year ending March 31, 1949, and thus corresponds to about one-tenth of the country's coal consumption. The British Electrical and Allied Industries Research Association and the North of Scotland Hydro-Electric Board have arranged for the erection of a $100-\mathrm{kW}$. wind-driven generator in the Orkneys as a pilot plant.

The oil industry provides a striking example of conservation of existing resources and of discovery of new reserves more than keeping pace even with present-day leaping requirements. Technical skill has overcome the challenge of maintaining supplies at a level that has met unprecedented demands. The depth from which oil is obtained has increased from 2,314 metres in 1925 to 6,270 metres. The submerged sea areas bordering the North American continent represent an "assured source of large quantities of petroleum". Drilling and production practice has been greatly improved. One most important advance has been the development of reservoir engineering with the object of so guiding tne exploitation and operation of oil reservoirs as to achieve maximum recovery at minimum cost.

The production of energy from nuclear fission is exercising keen minds, at great cost, in many lands. The method visualized is the transfer of heat from a nuclear reactor through a suitable medium (helium under pressure being favoured at present) to the boiler unit of a conventional power-generating system. Nuclear reactors must be devised which will develop heat at a temperature high enough to produce high thermodynamic efficiencies; the reactors must utilize nuclear fuel efficiently; the reactor life must be long enough to keep interest and depreciation charges to a reasonable level ; overall operating costs, including costs of providing and processing nuclear fuel, must be comparable with costs of power stations of conventional design. Among the more important scientific factors is the need to 'breed' more secondary nuclear fuel within the pile than primary fuel consumed; a difference of opinion was observed at the conference on the extent to which this can be done at present. Engineers asked pertinent questions on the stability of constructional materials under pile conditions, since the whole of the plant must be within a protective casing. Existing power plant requires frequent inspection and maintenance; it is asked how the problems of lubrication and maintenance can be overcome under atomic-pile conditions, where both circulating system and prime mover are inaccessible. Reactors under construction in the United States and Britain are expected to provide information on the many scientific and engineering problems involved; but an American author confessed that the technical problems in power generation from nuelear fission "are proving to be more difficult than was expected three years ago".

The sections dealing with the preparation of solid fuels discussed coals, sub-bituminous coals and peat, 
and coke. Modern mechanical coal mining is bringing to the surface material containing a greater proportion of dirt and a larger quantity of fines. The use of water underground for dust suppression seems likely to cause the total disappearance of dry-cleaning systems. New wet-washing methods, such as densemedium processes and froth-flotation, combined with older established methods now enable any size of coal to be cleaned; the immediate problem in many countries is to erect suitable and sufficient coal. cleaning plant at a reasonable cost and in reasonable time. How far fines should be cleaned and how far they should be used in the uncleaned state for powdered-fuel firing remains a difficult economic question. The tendency in Britain is to erect large central washeries. Coal cleaning is becoming a specialist subject. The National Coal Board has adopted a practical classification of British coals based on rank, yield of volatile matter and coking property, and has brought into use the standard size grading of the former British Colliery Owners' Research Association, in which only seven sizes above $\frac{1}{8}$ in. are recognized for marketing purposes. There is a difference of opinion between nations possessing peat deposits as to whether the winning of peat is economical ; the utilization of peat is under examination in several countries. Brown coals and lignites, which were extensively developed in Germany, are now being used for boiler firing in Australia, Czechoslovakia, Yugoslavia and elsewhere, and efforts are being made to dry and briquette it economically or to carbonize it.

All nations possessing coking coals are finding that their reserves of good coking coals are running low. Research is being undertaken on the use of the poorer coking coals for making blast furnace coke. Fine grinding of the coals, blending of coking with poorly coking or non-coking coals or with semi-coke, and two-stage processes often involving pre-carbonization followed by briquetting and re-carbonization are favoured. Economics, including cost of transport and manufacturing costs, dictate which, if any, of these processes can be used, even when they are technically sound. The possibility is envisaged of devising a low-cost method of iron-making that does not require hard coke.

Advances in the petroleum industry have been due to increasing demand for gasoline both in quantity and quality. Catalytic eracking is replacing thermal processing. The low efficiency ( 6 per cent) of gasoline used for transportation has led to increased engine compression ratio, which in turn necessitates gasoline of much higher octane number-an expensive matter-as an alternative to which manufacturers are endeavouring to improve the efficiency of the use of gasoline, for example, by a small super-charged engine, together with after-cooling, an exhaust gas turbine, and an automatic transmission. The application of chemical synthesis is a feature of the modern petroleum industry, including polymerization, alkylation, isomerization, superfractionation, catalytic cracking and hydro-reforming. Synthetic production of liquid fuels from coal, brown coal, etc., is being intensively studied; but these processes are only likely to be used industrially when supplies of natural oil become less than demand. The view was expressed that ultimately coal would be used solely as the raw material for the manufacture of oil for the internal combustion engine, other sources of energy being developed to replace coal for its present uses.
Natural gas-once largely wasted-is now making an increasingly large contribution to energy requirements both in America and Europe. It is used as fuel for industrial and domestic purposes, in the compressed state as a substitute for gasoline, as raw material for manufacture of chemical products and of synthesis gas for synthetic liquid fuel production, and as a source of hydrogen for synthetic ammonia manufacture. Interest is being taken in the recovery of methane from coal seams, partly to reduce the fire-damp concentration in gassy mines.

There is increasing use in many countries of the lower grades of fuel in large steam-raising units ; this leads to problems of boiler availability and size, of ash and grit disposal, to increased capital cost and possible reduced efficiency. Pulverized fuel firing is favoured, largely because of its flexibility, for larger boilers; but it has limitations with low-volatile coals. High steam pressures and temperatures, for example, up to $2,133 \mathrm{lb}$./sq. in. and $968^{\circ} \mathrm{F}$., are ranked high among means of securing greater economy; in Britain, 81 per cent of the new plant is designed for two standard conditions: $600 \mathrm{lb} / \mathrm{sq}$. in., $850^{\circ} \mathrm{F}$. and $900 \mathrm{lb}$./sq. in., $900^{\circ} \mathrm{F}$.; some new British plant will operate between $1,235 \mathrm{lb}$./sq. in., $825^{\circ} \mathrm{F}$. and $1,500 \mathrm{lb} . / \mathrm{sq}$. in., $1,050^{\circ} \mathrm{F}$. The Americans have plants running with steam at pressures of 1,800 and $2,000 \mathrm{lb}$./sq. in. and many plants are designed for steam at $1,050^{\circ} \mathrm{F}$. These conditions are permitted by the use of newer steels, mainly ferritic, with greater high-temperature strength. There is a tendency to use larger turbo-generators and larger boilers; in Britain, many $60-\mathrm{MW}$. and a few 100-MW. machines are under construction. In the United States, the trend towards the single boiler-turbine combination has involved steaming capacities up to $1,370,000$ lb./hr. The higher capital charges involved in burning low-grade fuels have been mitigated by more suitable design supplemented by better methods of on-load cleaning. The cyclone furnace has increased in popularity when the ash-fusion temperature of the fuel has been suitable. Spreader stokers are increasingly used for lower capacities. The natural-circulation boiler seems to hold its own over forcedcirculation and other competitors. Greater use is made of re-heat. Series of papers discussed the design of turbines and auxiliaries, and the use of fuels other than coal for steam-raising, for example, wood, brown coal, peat, town refuse and vegetable waste.

The wide variety of uses to which the gas turbine is put were reflected in the interest aroused by the discussion. Its future utilization depends on its ability to burn cheap fuel, and in all countries the development is towards using as gas turbine fuel coal or residual oil, and, in Britain, peat. Deleterious gaseous matter may cause difficulties, and it is not yet certain whether the largest size of particle which can be permitted to reach the turbine blades is $10 \mu$ or as high as $20 \mu$. Exhaust gases from high-temperature processes can be used for power generation, and the turbine can supply as exhaust low-temperature gases for drying, or pre-heated air for furnaces. The open cycle is generally adopted; but many believe that more emphasis should be put on the closed cycle. A second noticeable feature is the almost universal adoption of the axial-flow compressor. The gas turbine is clearly still in a comparatively early stage in its development; we cannot yet design a machine to run successfully and consistently on any given fuel. G. E. Foxweld 